\title{
Original article \\ Dual task and postural control in Alzheimer's and Parkinson's disease
}

\author{
Larissa Pires de Andrade \\ Natália Madalena Rinaldi \\ Flávia Gomes de Melo Coelho \\ Kátia Tanaka \\ Florindo Stella \\ Lilian Teresa Bucken Gobbi \\ São Paulo State University, Brazil
}

\begin{abstract}
Patients with neurodegenerative diseases are required to use cognitive resources while maintaining postural control. The aim of this study was to investigate the effects of a frontal cognitive task on postural control in patients with Alzheimer, Parkinson and controls. Thirty-eight participants were instructed to stand upright on a force platform in two experimental conditions: single and dual task. Participants with Parkinson's disease presented an increase in the coefficient of variation greater than $100 \%$ in the dual task as compared to the single task for center of pressure (COP) area and COP path. In addition, patients with Parkinson's and Alzheimer's disease had a higher number of errors during the execution of the cognitive task when compared to the group of elderly without neurodegenerative diseases. The motor cortex, which is engaged in postural control, does not seem to compete with frontal brain regions in the performance of the cognitive task. However, patients with Parkinson's and Alzheimer's disease presented worsened performance in cognitive task.
\end{abstract}

Key words: postural control, dual task, Alzheimer's disease, Parkinson's disease

Resumo - “Tarefa dupla e controle da postura na doença de Alzheimer e na doença de Parkinson". Pacientes com doenças neurodegenerativas utilizam recursos cognitivos para manutenção do controle postural. O objetivo deste estudo foi investigar os efeitos de uma tarefa cognitiva frontal no controle postural em pacientes com Alzheimer, com Parkinson e idosos sem doenças neurodegenerativas. Trinta e oito participantes foram instruídos a ficar em pé sobre uma plataforma de força em duas condições experimentais: tarefa simples e tarefa dupla com uma tarefa cognitiva frontal. Foi observado aumento no coeficiente de variação superior a $100 \%$ na área e na trajetória do centro de pressão (COP) em condição de tarefa dupla em pacientes com Parkinson. Foi observada também, diferença significativa na comparação entre grupos, mostrando que pacientes com Parkinson e Alzheimer tiveram maior número de erros durante a execução da tarefa cognitiva, quando comparado ao grupo de idosos sem doenças neurodegenerativas. O córtex motor envolvido na manutenção do controle postural parece não competir com regiões frontais cerebrais no desempenho desse tipo de tarefa cognitiva, no entanto, os pacientes com doença de Parkinson e doença de Alzheimer apresentaram pior desempenho durante a execução de uma tarefa cognitiva frontal.

Palavras-chave: controle da postura, tarefa dupla, doença de Alzheimer, doença de Parkinson

Resumen - "Doble tarea y el control postural en la enfermedad de Alzheimer y la enfermedad de Parkinson". Pacientes con enfermedades neurodegenerativas utilizan de recursos cognitivos para el mantenimiento del control postural. El objetivo de este estudio fue investigar los efectos de una tarea cognitiva frontal en el control postural de pacientes con enfermedad de Alzheimer, enfermedad de Parkinson y ancianos sin enfermedades neurodegenerativas. Treinta y ocho participantes fueron instruidos para mantenerse en pie sobre una plataforma de fuerza en dos condiciones experimentales: tarea simple y doble tarea con una tarea cognitiva frontal. Hubo un aumento en el coeficiente de variación superior a $100 \%$ en el área y en la trayectoria del centro de presión (CP) en condiciones de doble tarea en los pacientes con Parkinson. También fue observada diferencia significativa entre los grupos, revelando que los pacientes con Parkinson y Alzheimer tuvieron un número de errores más grande durante la realización de la tarea cognitiva en comparación con el grupo de sujetos sin enfermedades neurodegenerativas. La corteza motora que participa en el mantenimiento del control postural parece no competir con las regiones frontales del cerebro en el rendimiento de este tipo de tarea cognitiva, sin embargo, los pacientes con enfermedad de Parkinson y la enfermedad de Alzheimer presentaron peor rendimiento durante la ejecución de una tarea cognitiva frontal.

Palabras clave: control postural, doble tarea, enfermedad de Alzheimer, enfermedad de Parkinson 


\section{Introduction}

To date, little research has been done on the effects of completing dual tasks on postural control in patients with neurodegenerative diseases, especially in the case of Alzheimer's (AD) and Parkinson's diseases (PD). The dual task paradigm has been evaluated through the use of posturography in elderly patients without dementia, particularly with regards to the effects of different cognitive tasks on postural control. Even though, the results of these studies appear to be controversial because some report a reduction in body sway during execution of cognitive tasks (Huxhold, Li, Schmiedek, \& Lindenberg, 2006), and others observed increased postural instability in older individuals (Teasdale \& Simoneau, 2001; Marsh \& Geel, 2000; Brauer, Wollacott, \& Shumway-Cook, 2002; Jamet, Deviterne, Gauchard, Vançon, \& Perrin, 2006; Doumas, Smolders, \& Krampe, 2008).

Specifically in neurodegenerative diseases, when performing a memory task, patients with $\mathrm{AD}$ and their healthy controls showed worse performance in the postural control as compared to the cognitive task (Manckoundia, Pfitzenmeyer, d'Athis, Dubost, \& Mourey, 2006; Raap, Krampe, \& Baltes, 2006). In PD patients, there are some reports involving dual task performance, but the results of these studies are inconclusive. A study by Holmes, Jenkins, Johnson, Adams, and Spaulding (2010) found that patients with PD had significantly reduced trajectories of body sway when compared with subjects without neurodegenerative diseases in dual task situations involving postural control procedures performed concomitantly with two cognitive tasks, including numerical counting and reciting a monologue. The authors attributed the reduction of body sway to the dual task phenomenon of over-constraining. That is, when subjects are faced with the challenge of performing dual tasks, they would prioritize postural control and favor the maintenance of balance. However, these results conflict with other studies that reported an increase in postural instability when performing dual tasks in patients with PD (Marchese, Bove \& Abbruzzese, 2003; Morris, Iansek, Smithson \& Huxham, 2000).

It is known that postural control depends on several factors, including cognitive resources and postural guidance (Horak, 2006). In many situations, patients with neurodegenerative diseases are required to use cognitive resources while maintaining postural control. In this context, investigations based on posturography into the role of simultaneous cognitive and motor demands could contribute to the understanding of this complex issue.

Recently, Ebersbach and Gunkel (2011) showed that clinical posturography may reflect imbalances in PD. Although the main focus of this research was cognitive areas in the mesial temporal lobe in patients with $\mathrm{AD}$, studies have also described initial cognitive changes in frontal regions in these subjects. Possibly, in the early stages of AD there are alterations in the frontal region of the brain (Perry \& Hodges, 1999), including involvement of motor pathways (Sheridan \& Hausdorff, 2007). Obviously, in PD, motor abnormalities are characteristic components of the early clinical picture. However, attention is an important component in dual task context and it is impaired in people with AD and PD (Morris et al., 2000; Perry \& Hodges, 1999), which demonstrate the importance in comparing both groups in the impact of completing dual tasks on postural control. Therefore, this study was designed to investigate and compare the effects of frontal cognitive tasks on postural control in patients with Alzheimer's and Parkinson's disease without dementia and subjects without neurodegenerative diseases. Based on the literature, we hypothesized that both patients' groups would show poorer dual task performance, with AD patients performing worse on cognitive task due to impairment in the temporal region and patients with PD altering postural control due to allocating attention in the cognitive task.

\section{Methods}

\section{Ethical aspects}

The Committee of Ethics in Research of the Institute of Biosciences of UNESP (São Paulo State University, Rio Claro Campus) approved this research.

\section{Sample}

The study included 38 elderly people. Of these, 12 patients had clinical diagnoses of AD (72.2 \pm 5.3 years; nine women) based on the criteria of the Diagnostic and Statistical Manual of Mental Disorders (DSM-IV) and the International Classification of Diseases (ICD-10). Thirteen patients had been diagnosed with PD (71.7 \pm 6.1 years; 7 women). The patients already arrived at the university with a clinical diagnosis of Parkinson's disease by their physician. Thirteen elderly (control) subjects without a diagnosis of neurodegenerative diseases (65.8 \pm 4.5 years; 7 women) were also enrolled. Inclusion criteria to participate in the study were: 1) have the ability to walk independently, 2) patients with AD should have mild or moderate stage disease according to the Clinical Dementia Rating Scale (CDR) (Morris, 1993; Montaño \& Ramos, 2005), 3 ) patients with PD should be in stages 1 to 3 according to the Hoehn \& Yahr Scale (HY) (Goetz et al., 2004) and tested in the state on of the medication. The Mini-Mental State Examination (MMSE) (Folstein, 1975) was used to assess participants' cognitive function. Since all participants were enrolled in physical activity programs specifically designed for their conditions, the modified Baecke questionnaire (MBQ) (Voorrips, Ravelli, Dongelman, Deurenberg, \& Van Staveren, 1991) was used to assess the subjects' level of physical activity in relation to home care tasks, sports and leisure activities. The number of falls in last year was also recorded to observe its possible effect on postural control. Table 1 presents the baseline comparisons of the three groups (AD, PD and control).

\section{Tasks}

Participants were instructed to stand upright on a force platform with arms positioned along the body, to remain as still as possible, and to look at a target positioned one meter away at eye level. Subjects performed this task under two experimental conditions: 1) single task condition (ST) - gaze on the target 
Table 1. Mean, standard deviation ( \pm ), F and $\mathrm{p}$ interaction values for group characteristics as age, education, height, body mass, cognitive function, physical activity level and number of falls.

\begin{tabular}{lccccc}
\hline Groups & $\begin{array}{c}\text { Alzheimer's } \\
\text { disease } \\
(\mathrm{n}=12)\end{array}$ & $\begin{array}{c}\text { Parkinson's } \\
\text { disease } \\
(\mathrm{n}=13)\end{array}$ & $\begin{array}{c}\text { Control } \\
(\mathrm{n}=13)\end{array}$ & $\mathrm{F}$ & $\mathrm{p}$ \\
\hline Age (years) & $72.2 \pm 7.3$ & $71.7 \pm 6.1$ & $65.8 \pm 4.5$ & 3.0 & 0.06 \\
Schooling (years) & $6.2 \pm 3.7$ & $7.3 \pm 4.9$ & $8.4 \pm 4.3$ & 1.5 & 0.23 \\
Height (cm) & $160.6 \pm 7.0$ & $160.7 \pm 10.1$ & $162.9 \pm 8.6$ & 0.7 & 0.51 \\
Body Mass (kg) & $67.1 \pm 8.9$ & $63.1 \pm 12.6$ & $73.4 \pm 11.7$ & 2.6 & 0.08 \\
MMSE (points) & $20.7 \pm 4.0^{\mathrm{a}}$ & $27.7 \pm 2.2$ & $27.6 \pm 2.5$ & 24.6 & $0.01^{*}$ \\
MBQ (points) & $2.1 \pm 0.9$ & $3.3 \pm 3.7$ & $4.0 \pm 1.8$ & 1.3 & 0.29 \\
Falls & $0.2 \pm 0.4$ & $2.6 \pm 4.3^{\mathrm{b}}$ & $0.3 \pm 0.7$ & 3.69 & $0.05^{*}$ \\
\hline
\end{tabular}

MMSE: Mini Mental State Examination; MBQ: modified Baecke questionnaire; *p $<0.05$. aDifferent from Parkinson's disease and Control

'Different from Alzheimer's disease and Control

and arms alongside the body, and 2) dual task condition (DT) - the same conditions as ST while simultaneously performing the cognitive task of counting backwards by one digit from 30. Even with low cognitive load, this executive task was chosen to allow AD patients to complete it. All participants completed three trials of forty seconds each for each condition. The forty seconds in each trial was based on the longer time spent in the quiet, upright posture suggested by Lafond, Corriveau, Hébert, and Prince (2004) in comparison with the thirteen seconds used by Manckoundia et al. (2006) in patients with AD.

The distance between the legs was established as the individual pelvic width (Termoz et al., 2008). To ensure the same placement of feet between trials, a piece of paper was used to draw the participant's feet position on the force platform. To ensure that these procedures were suitable for data acquisition, a preliminary procedure was performed with a patient with $\mathrm{AD}$, enabling us to proceed with the evaluation protocol for all participants.

\section{Equipment}

A force platform (AMTI model AccuGait) with an acquisition frequency of $100 \mathrm{~Hz}$ was used to evaluate postural control. The sensors under the force plate measured three force components (Fx, Fy and Fz) and three moment of force components (Mx, My and Mz) (x, y and $\mathrm{z}$ directions are the anterior-posterior, medio-lateral and vertical, respectively). Based on this forces and moments, the center of pressure (COP), in anterior-posterior and medio-lateral directions, was calculated by the AMTI's Balance Clinic software. COP data were filtered through a $4^{\text {th }}$ order low-pass Butterworth filter, with a cut-off frequency of 5 $\mathrm{Hz}$ (Knapp, Lee, Chinn, Saliba, \& Hertel, 2011). The filtering process was performed using custom routine written in Matlab (Math Works, Inc., version 7).

\section{Data treatment}

Data processing and computation of variables were performed using a routine written in MATLAB language (Math Works, Inc., version 7). To evaluate differences in body sway for the three groups under two experimental conditions, we used two variables to describe COP: path (which represents the total length of the COP trajectory on the support base) and ellipse area (which estimates the COP data dispersion, fitting an ellipse to $95 \%$ of the COP data points). This analysis represents a map
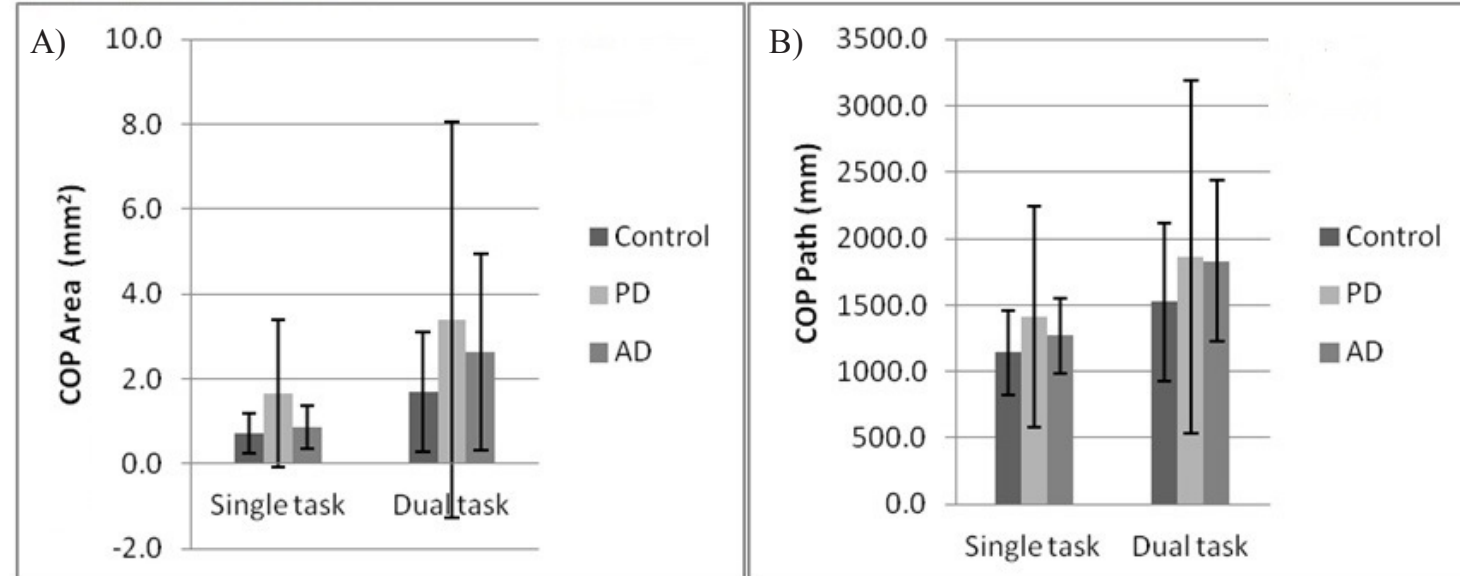

Figure 1. Means and standard deviations for COP area (a) and COP path (b) for the three tested groups (Control; PD: Parkinson's disease; AD: Alzheimer's disease) in both single and dual tasks conditions. 
Table 2. Coefficient of variation (\%) for COP area and COP path for the three tested groups in both single and dual tasks conditions.

\begin{tabular}{lcccccc}
\hline & \multicolumn{3}{c}{ Single task } & \multicolumn{3}{c}{ Dual task } \\
\cline { 2 - 7 } & $\begin{array}{c}\text { Alzheimer's } \\
\text { disease }\end{array}$ & $\begin{array}{c}\text { Parkinson's } \\
\text { disease }\end{array}$ & Control & $\begin{array}{c}\text { Alzheimer's } \\
\text { disease }\end{array}$ & $\begin{array}{c}\text { Parkinson's } \\
\text { disease }\end{array}$ & Control \\
\hline COP area & 57 & $104^{*}$ & 63 & 88 & $137^{*}$ & 83 \\
COP path & 22 & 59 & 28 & 33 & 71 & 39 \\
\hline
\end{tabular}

*Coefficient of variation greater than $100 \%$.

of the COP in both directions. In the DT condition, the numbers in the cognitive task were recorded to control the number of errors for each trial.

\section{Statistical analysis}

First, to determine whether the data were normally distributed, we used the Shapiro-Wilk test. Once the data were not normally distributed, the Z-score was calculated to reduce the dispersion of data and the execution of parametric tests could be possible. Then, we performed a descriptive analysis (mean and standard deviation) and parametric MANOVA test to observe the interaction among groups (control, PD and AD) and conditions (simple task and dual task) and one-way ANOVA to verify the variables age, schooling, height, body mass, MMSE, MBQ and number of falls at baseline among groups (control, $\mathrm{PD}$ and $\mathrm{AD}$ ). The number of errors committed during execution of the cognitive task under dual task condition was compared between the three groups by the Kruskal-Wallis and then the Mann-Whitney tests. Analyses were performed using SPSS (SPSS for Windows - Version 18.0). The level of significance for all tests was set at $\alpha<0.05$.

\section{Results}

Table 1 shows the general characteristics of the three groups at the time of the study, such as age, education, height, body mass, cognitive function, physical activity level and number of falls in the last year. One-way ANOVA showed that only cogni-

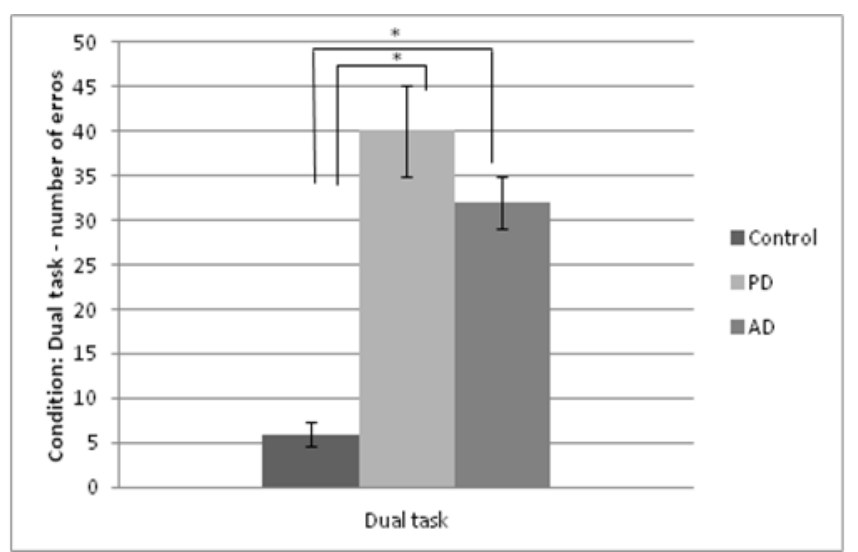

Figure 2. Number of errors in the cognitive task under dual task condition for the three tested groups (Control; PD: Parkinson's disease; AD: Alzheimer's disease). $\left({ }^{*} p \leq 0.05\right)$ tive variables and number of falls were different among groups.

MANOVA showed no significant interactions between groups (control, PD and AD) and conditions (single task and dual task) for the COP variables path $\left(F_{1,35}=0.01 ; p=0.98\right)$ and area $\left(F_{1,35}=0.02 ; p=0.96\right)$ (Figure 1).

Since there was high variability for the dual task condition, we calculated the coefficient of variation $(\mathrm{CV}=100 * \mathrm{SD} / \mathrm{M})$ for all COP variables by group and conditions. As shown in Table 2 , the coefficients of variation of the $\mathrm{COP}$ area was greater than $100 \%$ in the single and dual task conditions in the PD group.

For the number of errors committed during the cognitive task in the dual task condition, the Kruskal-Wallis test revealed a significant difference among groups $(p=0.02)$. The Mann-Whitney post hoc tests revealed significant differences between control and $\mathrm{PD}(p=0.02)$ groups and between control and $\mathrm{AD}(p=$ $0.001)$ groups. Alzheimer's and Parkinson's patients committed more errors than control group individuals when performing the cognitive task in the dual task condition (Figure 2).

\section{Discussion}

The aim of this study was to analyze the effects of performing a frontal cognitive task on postural control in patients with Alzheimer's disease and Parkinson's compared with older adults without a diagnosis of neurodegenerative disease. There were no significant differences in any COP variables among the groups in the two experimental conditions. However, we found a significant increase in the number of errors during the cognitive task in the dual task condition in patients with Alzheimer's and Parkinson's disease compared to the control group. An increased coefficient of variation in some COP variables from single to dual task condition, especially in people with $\mathrm{PD}$, was also observed.

Our results are consistent with the principle of priority of position, i.e., when the individual is involved in a situation requiring simultaneous performance of two or more tasks, such as maintaining posture and performing a cognitive task, attention tends to be allocated to control postural stability, resulting in a tendency towards impaired performance on the cognitive task (Shumway-Cook, Woollacott, Kerns, \& Baldwin, 1997; Raap et al., 2006). This phenomenon could explain the increase in errors committed during execution of the cognitive task in groups of patients with Alzheimer's and Parkinson's disease in this study. Probably to ensure postural stability, these patients do not prioritize successful completion of the cognitive task.

In contrast, a review by Bloem, Grimbergen, Dijk, and Munneke (2006) analyzed studies that investigated the performance of 
patients with Parkinson's disease in situations of concurrent tasks. Seven out of ten studies examined the performance of a cognitive task and/or a motor task. Only three studies have evaluated the effects of performing dual tasks on static posture, measured by a force platform. The results showed that PD patients use the strategy of "second posture", giving priority to the cognitive task (Bloem et al., 2006). That is, posture and gait are treated as secondary to the cognitive and/or motor task prioritized above it, which may favor the occurrence of falls. However, the study by Holmes et al. (2010) compared the postural stability of patients with PD and subjects without neurodegenerative diseases, while performing different cognitive tasks (postural control task concurrently with the task of counting and reciting a monologue, with increased complexity). Patients with PD showed a significant decrease in COP path compared to controls. These results suggest that patients with PD exhibit the phenomenon of "over-constraining", meaning that in dangerous situations, they prioritize postural stability in an attempt to prevent accidents, especially when resources are allocated to cognitive cortical functions.

In patients with PD, "over-constraint" can be further aggravated by impaired sensory integration (Brown et al., 2006), one of the functions of the basal ganglia. Due to the death of dopaminergic neurons, the dopaminergic pathways in the thalamus and cerebral cortex would be affected and consequently undermine control of movement and posture. Moreover, the involvement of cholinergic pathways, which originate in the pedunculopontine nucleus located in the brain stem, may also influence control of postural oscillations (Bohnen et al., 2009). These mechanisms may explain, in part, the prioritization of posture and the significantly higher number of cognitive errors compared to other groups. Then, PD patients have a higher number of errors due to prioritization of postural control and not by cognitive impairment, since they present the cognitive state preserved. In this sense, the cognitive function, assessed by the MMSE at baseline was not significantly different between patients with PD and the control group. Another important consideration is the high number of falls in patients with PD (Table 1), which is significantly higher than in other groups. Patients with PD are prone to falls, although they tend to prioritize competing tasks. Even though people with PD in early stages of the disease showed almost intact mechanisms of balance control in challenging walking tasks (Caetano, Gobbi, Sanchez-Arias, Stella, \& Gobbi, 2009; Vitório, Pieruccini-Faria, Stella, Gobbi, \& Gobbi, 2010), our PD patients revealed that, under dual task condition, the cognitive and postural control may share the same brain regions. Another aspect that needs to be considered is the motor component in the cognitive task we used. Perhaps, talking and simultaneously controlling the posture can overload the motor system of the PD patients.

Patients with AD did not differ with respect to postural control while performing a simultaneous frontal cognitive task compared to the other groups (control and PD). It is important to consider that these patients were in the early disease stages and probably frontal cognitive functions were still preserved. AD begins with loss of cholinergic neurons in hippocampus and isocortex causing memory impairment (Braak, Griffing, Arai, Bohl, \& Bratzke, 1999). In this study, the task of maintaining posture was not challenging for patients with $\mathrm{AD}$ and their mechanisms of postural control seem to be intact.
Unlike the present study, Manckoundia et al. (2006) observed increased variability in both path trajectory and COP area in dual task situations, even in the early stages of AD. However, they used a memory task. In our work the AD patients revealed best performance in postural control, but we used an executive task for the dual task condition.

Interestingly in subjects without neurodegenerative diseases, we observed the same patterns in all variables of the COP as in the groups with PD and AD. Notably, these seniors did not have cognitive impairment, which would have required prioritizing either posture or the cognitive task. Subjects without neurodegenerative diseases were able to sustain the variability of less than $100 \%$ in all measures of COP and, at the same time, perform the cognitive task without significantly increasing errors when compared to AD and PD groups. These data show that elderly are more consistent compared to the other two groups. Huxhold et al. (2006) investigated different types of cognitive tasks in elderly subjects and noted that some cognitive tasks were not sufficient to cause changes in postural control, but when more attention was required, the postural control was prioritized and changes in COP decreased. Although the type of cognitive task used in this study was frontal and involved attention, this competition did not translate into important increase in postural instability for these elderly subjects.

\section{Conclusion and final thoughts}

Based on the results obtained in this study, we can conclude that the frontal cognitive task we tested did not cause changes in postural control mechanisms for the three groups (control, AD and PD) in the dual task condition. However, patients with PD had increased coefficients of variation (more than 100\%) in COP area in both conditions (single task and dual task). In addition, patients with $\mathrm{AD}$ and PD had significantly higher numbers of errors than elderly subjects without neurodegenerative diseases. The finding of no difference between conditions and among groups is relevant because, despite the significantly increased number of errors committed during the execution of the dual task in patients with AD and PD, all participants, regardless of which group they belonged, had similar performance in measures of postural control, suggesting that they all prioritized maintaining posture. However, it is worth noting that investigations into static postural control in dual task situations in patients with AD and PD are scarce, which makes it difficult to understand the mechanisms and pathways that can lead to falls in dual task situations in these patients.

Thus, further studies are necessary in order to investigate the mechanisms by which motor impairment and cognitive decline in AD and PD may interfere with postural stability in dual task situations. This could help to decrease and hopefully prevent falls in these patients.

\section{References}

Bloem, B. R., Grimbergen, Y. A. M., Dijk, G. V., \& Munneke, M. (2006). The "posture second" strategy: A review of wrong priorities in Parskinson's Disease. Journal of Neurological Sciences, 248, 196-204. 
Bohnen, N. I., Muller, M. L. T. M., Koeppe, R. A., Studenski, S. A., Kibourn, M. A., Frey, K. A., \& Albin, R. L. (2009). History of falls in Parkinson's disease is associated with reduced cholinergic activity. Neurology, 73, 1670-1676.

Braak, E., Griffing, K., Arai, K., Bohl, J., \& Bratzke, H. (1999). Neuropathology of Alzheimer's disease: what is new since A. Alzheimer? European Archives of Psychiatry and Clinical Neurosciences, 249, 14-22.

Brauer, S. G., Woollacott, M., \& Shumway-Cook, A. (2002). The influence of a concurrent cognitive task on the compensatory stepping response to a perturbation in balance-impaired and healthy elders. Gait \& Posture, 15, 83-93.

Brown, L. A., Cooper, S. A., Doan, J. B., Dickin, D. C., Whishaw, I. Q., Pellis, S. M., \& Suchowersky, O. (2006). Parkinsonian deficits in sensory integration for postural control: Temporal response to changes in visual input. Parkinsonism \& Related Disorders, 12, 376-381.

Caetano, M. J. D., Gobbi, L. T. B., Sanchez-Arias, M. R., Stella, F., \& Gobbi, S. (2009). Effects of postural threat on walking features of Parkinson's disease patients. Neuroscience Letters, 452, 136-140.

Doumas, M., Smolders, C., \& Krampe, R. T. (2008). Task prioritization in aging: effects of sensory information on concurrent posture and memory performance. Experimental Brain Research, 187, 275-281.

Ebersbach, G., \& Gunkel, M. (2011). Posturography reflects clinical imbalance in Parkinson's disease. Movement Disorders, 26, 241-246.

Folstein, M. F. (1975). Mini Mental State. A practical method for grading the cognitive state of patients for the clinicians. Journal of Psychiatric Research, 12, 189-198.

Goetz, C. G., Poewe, W., Rascol, O., Sampaio, C., Stebbins, G. T., Counsell, C., . . . Seidl, L. (2004). Movement Disorder Society Task Force Report on the Hoehn and Yahr Staging Scale: Status and Recommendations. Movement Disorders, 19, 1020-1028.

Holmes, J. D., Jenkins, M. E., Johnson, A. M., Adams, S. G., \& Spaulding, S. J. (2010). Dual-task interference: The effects of verbal cognitive tasks on upright postural stability in Parkinson's Disease. Parkinson's Disease, 10, 1-5.

Horak, F. B. (2006). Postural orientation and equilibrium: what do we need to know about neural control of balance to prevent falls? Age and Ageing, 35, ii7-ii11.

Huxhold, O., Li, S. C., Schmiedek, F., \& Lindenberg, U. (2006). Dual-tasking postural control: Aging and the effects of cognitive demand in conjunction with focus of attention. Brain Research Bulletin, 69, 294-305.

Jamet, M., Deviterne, D., Gauchard, G., Vançon, G., \& Perrin, P. P. (2006). Age-related part taken by attentional cognitive processes in standing postural control in a dual-task context. Gait \& Posture, 25, 179-184.

Knapp, D., Lee, S. Y., Chinn, L., Saliba, S. A., \& Hertel, J. (2011). Differential ability of selected postural control measures in the prediction of chronic ankle instability status. Journal of Athletic Training, 46, 257-262.

Lafond, D., Corriveau, H., Hébert, R., \& Prince, F. (2004). Intrasession reliability of center of pressure measures of postural steadiness in healthy elderly people. Archives Physical Medicine and Rehabilitation, 85, 896-901.

Manckoundia, P., Pfitzenmeyer, P., d'Athis, P., Dubost, V., \& Mourey, F. (2006). Impact of cognitive task on the posture of elderly subjects with Alzheimer's disease compared to healthy elderly subjects. Movement Disorders, 21, 236-273.

Marchese, R., Bove, M., \& Abbruzzese, G. (2003). Effect of cognitive and motor tasks on postural stability in Parkinson's disease: A Posturographic Study. Movement Disorders, 18, 652-658.

Marsh, A. P., \& Geel, S. E. (2000). The effect of age on the attentional demands of postural control. Gait \& Posture, 12, 105-113.

Montaño, M. B. M. M., \& Ramos, L. R. (2005). Validade da versão em português da Clinical Dementia Rating (CDR). Revista de Saúde Pública, 39, 912-917.

Morris, J. (1993). The Clinical Dementia Rating (CDR): current version and scoring rules. Neurology, 43, 2412-2414.

Morris, M. E., Iansek, R., Smithson, F., \& Huxham, F. (2000). Postural instability in Parkinson's disease: a comparison with and without a concurrent task. Gait \& Posture, 12, 205-216.

Perry, R. J., \& Hodges, J. R. (1999). Attention and executive deficits in Alzheimer's disease. Brain, 122, 383-404.

Raap, M. A., Krampe, R. T., \& Baltes, P. B. (2006). Adaptive task priorization in aging: Selective resource allocation to postural control is preserved in Alzheimer Disease. American Journal of Geriatric Psychiatry, 14, 52-61.

Sheridan, P. L., \& Hausdorff, J. M. (2007). The role of higher - level cognitive function in gait: Executive dysfunction contributes to fall risk in Alzheimer's disease. Dementia and Geriatric Cognitive Disorders, 24, 125-137.

Shumway-Cook, A., Woollacott, M., Kerns, K. A., \& Baldwin, M. (1997). The effects of two types of cognitive tasks on postural stability in older adults with and without a history of falls. The Journal of Gerontology Series A: Biological Sciences and Medical Sciences, 52, 232-240.

Teasdale, N., \& Simoneau, M. (2001). Attentional demands for postural control: The effects of aging and sensory reintegration. Gait \& Posture, 14, 203-210.

Termoz, N., Halliday, S., Winter, D. A., Frank, J. S., Patla, A. E., \& Prince, F. (2008). The control of upright stance in young, elderly and persons with Parkinson's disease. Gait \& Posture, 27, 463-470.

Vitório, R., Pieruccini-Faria, F., Stella, F., Gobbi, S., \& Gobbi, L. T. B. (2010). Effects of obstacle height on obstacle crossing in mild Parkinson's disease. Gait \& Posture, 31, 143-146.

Voorrips, L. E. A., Ravelli, A. C. J., Dongelmans, P. C. A., Deurenberg, P., \& Van Staveren, W. A. (1991). A Physical activity questionnaire for the elderly. Medicine and Science in Sports and Exercise, 12, 328-329.

\section{Authors' note}

Larissa Pires de Andrade is with the Physical Activity and Aging Lab (LAFE), Department of Physical Education, São Paulo State University, Rio Claro, São Paulo, Brazil.

Natália Madalena Rinaldi is with the Posture and Gait Studies Laboratory (LEPLO), Department of Physical Education, São Paulo State University, Rio Claro, São Paulo, Brazil.

Flávia Gomes de Melo Coelho is with the Physical Activity and Aging Lab (LAFE), Department of Physical Education, São Paulo State University, Rio Claro, São Paulo, Brazil.

Kátia Tanaka is with the Physical Activity and Aging Lab (LAFE), Department of Physical Education, São Paulo State University, Rio Claro, São Paulo, Brazil.

Florindo Stella is with the Physical Activity and Aging Lab (LAFE), Department of Physical Education, São Paulo State University, Rio Claro, São Paulo, Brazil and the Clinic of Geriatric Psychiatry, Campinas State University, Campinas, São Paulo, Brazil.

Lilian Teresa Bucken Gobbi is with the Posture and Gait Studies Laboratory (LEPLO), Department of Physical Education, São Paulo State University, Rio Claro, São Paulo, Brazil. 


\section{Corresponding author:}

Lilian Teresa Bucken Gobbi

UNESP - Universidade Estadual Paulista, Instituto de Biociências /

Caixa Postal: 199

13506-900 - Rio Claro, SP, Brazil

Phone: +55193534.6436

Fax: +55193534.6436

ltbgobbi@rc.unesp.br

Acknowledgements:

FAPESP, CAPES, FINEP, FNS-MS, FUNDUNESP, PROEXUNESP and LAFE

Manuscript received on March 29, 2013

Manuscript accepted on January 16, 2014 